\title{
Intermediate phase-enhanced Ostwald ripening for the elimination of phase segregation in efficient inorganic $\mathrm{CsPblBr}_{2}$ perovskite solar cells
}

Wei $\mathrm{Li}^{1,2}$, Benjia Zhu ${ }^{1,2}$, Mathias Uller Rothmann ${ }^{3}$, Amelia Liu ${ }^{4}$, Weijian Chen ${ }^{5}$, Yen Yee Choo ${ }^{6,7}$, Narendra Pai ${ }^{8}$, Wenxin Mao ${ }^{6,8}$, Tian Zhang ${ }^{6,8}$, Qiaoliang Bao ${ }^{7}$, Xiaoming Wen ${ }^{5}$, Udo Bach ${ }^{6,8,9,10^{*}}$, Joanne Etheridge $e^{7,11^{*}}$ and Yi-Bing Cheng ${ }^{1,2^{*}}$

\begin{abstract}
Mixed halide perovskites with the ability to tune bandgaps exhibit attractive applications in tandem solar cells, building integrated photovoltaic and wavelength-tunable light-emitting devices. However, halide demixing under illumination or in the dark with a charge-carrier injection in both hybrid and inorganic perovskites results in bandgap instability and current-density-voltage $(J-V)$ hysteresis, which can significantly hamper their application. Here, we demonstrate that halide segregation and $J-V$ hysteresis in mixed halide inorganic $\mathrm{CsPbIB}_{2}$ solar cells can be effectively mitigated by introducing an intermediate phase-enhanced Ostwald ripening through the control of the chemical composition in the $\mathrm{CsPIBr}_{2}$ precursor solution. Excess amounts of either $\mathrm{PbBr}_{2}$ or CsI are incorporated into originally even molar amounts of $\mathrm{PbBr}_{2}$ and CsI precursor solutions. With the $\mathrm{PbBr}_{2}$-excess, we observed an enlarged perovskite grain size, no detectable halide phase segregation at the grain boundaries nor the perovskite/ $/ \mathrm{TiO}_{2}$ interface, an increased minority carrier lifetime, a reduced $J-V$ hysteresis, and an improved solar-cell performance. However, different $\mathrm{CsI}: \mathrm{PbBr}_{2}$ stoichiometric ratios were found to have different effects on the performance of the perovskite solar cell. The excessive lead phase is reactive with
\end{abstract}

the dimethyl sulfoxide (DMSO) in the precursor solution to form the $\mathrm{Pb}(\mathrm{I}, \mathrm{Br})_{2} \cdot \mathrm{DMSO}$ complex and the quasi-twodimensional (2D) $\mathrm{CsPb}_{2}(\mathrm{I}, \mathrm{Br})_{5}$, which are conducive to Ostwald maturation and defect extinction. Finally, the $\mathrm{CsPbIr}_{2}$ solar cell with a $\mathrm{PbBr}_{2}$-excess precursor composition reaches a power conversion efficiency (PCE) of 9.37\% (stabilized PCE of 8.48\%) and a maximum external quantum efficiency of over $90 \%$.

Keywords: solar cells, phase segregation, $\mathrm{CsPbIr}_{2}$, cathodoluminescence, transmission electron microscope

\section{INTRODUCTION}

Photoactive materials with the perovskite structure show great potential in the next-generation photovoltaics and optoelectronics. In particular, the ability to tune bandgaps with adjustments of the composition is one of the most attractive properties for their potential applications in tandem solar cells [1], building integrated photovoltaics [2], and wavelength-tunable light-emitting devices (LEDs) [3]. The bandgap of perovskite absorbers can be continuously tuned from approximately 1.2 to $2.3 \mathrm{eV}$ by

${ }^{1}$ Foshan Xianhu Laboratory of the Advanced Energy Science and Technology Guangdong Laboratory, Xianhu hydrogen Valley, Foshan 528200, China

${ }^{2}$ State Key Laboratory of Advanced Technology for Materials Synthesis and Processing, Wuhan University of Technology, Wuhan 430070, China

${ }^{3}$ Department of Physics, University of Oxford, Oxford OX1 3PU, United Kingdom

${ }^{4}$ School of Physics and Astronomy, Monash University, Victoria 3800, Australia

${ }^{5}$ Centre for Micro-Photonics, Swinburne University of Technology, Hawthorn 3122, Australia

${ }^{6}$ Australian Research Council Centre of Excellence in Exciton Science, Monash University, Victoria 3800, Australia

${ }^{7}$ Department of Materials Science and Engineering, Monash University, Victoria 3800, Australia

${ }^{8}$ Department of Chemical Engineering, Monash University, Victoria 3800, Australia

${ }^{9}$ Commonwealth Scientific and Industrial Research Organization, Manufacturing Flagship, Clayton, Victoria 3168, Australia

${ }^{10}$ Melbourne Centre for Nano fabrication, 151 Wellington Road, Clayton, VIC 3168, Australia

${ }^{11}$ Monash Centre for Electron Microscopy, Monash University, Victoria 3800, Australia

*Corresponding authors (emails: yibing.cheng@whut.edu.cn (Cheng YB); joanne.etheridge@monash.edu (Etheridge J); udo.bach@monash.edu (Bach $\mathrm{U})$ ) 
varying the composition of the $\mathrm{ABX}_{3}$ formula, with $\mathrm{A}$ cations, such as methylammonium $\left(\mathrm{CH}_{3} \mathrm{NH}_{2}^{+}\right)$, formamidinium $\left(\mathrm{CH}\left(\mathrm{NH}_{2}\right)_{2}{ }^{+}\right)$, and cesium $\left(\mathrm{Cs}^{+}\right)$; B cations such as tin $\left(\mathrm{Sn}^{2+}\right)$ and lead $\left(\mathrm{Pb}^{2+}\right)$; and halides, such as iodide $\left(\mathrm{I}^{-}\right)$, bromide $\left(\mathrm{Br}^{-}\right)$, and chloride $\left(\mathrm{Cl}^{-}\right)$, as the $\mathrm{X}$ anion $[4,5]$. However, both hybrid and inorganic perovskites with a large bandgap are subject to bandgap instability due to halide demixing under illumination or in the dark with charge-carrier injection [6-9]. Halide segregation can prevent the achievement of spectrally stable LED devices [10] and, also, potentially enhance ion migration and alter the electric-field gradients within the solar cell, negatively influencing the performance and stability of the device $[8,11-14]$.

Halide segregation within an initially perfect single crystal, such as $\mathrm{CsPbI}_{3-x} \mathrm{Br}_{x}$, is not energetically favorable as a large lattice mismatch exists between the iodide-rich and bromide-rich phases [15]. However, near a defect, such as a grain boundary (GB), the lattice mismatch may be more easily accommodated with a lower energy penalty. Furthermore, the formation energy of the point defects at the GBs, and the film's surfaces can be much lower than that in the grain interiors [16,17]. In our previous study, cathodoluminescence (CL) was employed to further reveal the nanoscale halide phase segregation in inorganic $\mathrm{CsPbIr}_{2}$, in which the iodide-rich $\mathrm{CsPbI}_{1+x} \mathrm{Br}_{2-x}$ phases were identified to segregate at the GBs [8]. The crystalline defects, typically halide vacancies and interstitials, promoted halide migration and segregation by providing low-energy migration pathways that could potentially lead to current-density-voltage $(J-V)$ hysteresis [17-19]. Furthermore, a free carrier trapped at the defective GBs with a low bandgap, such as the iodiderich phase of $\mathrm{CsPbI}_{3-x} \mathrm{Br}_{x}$, could greatly increase the recombination rate [20].

Therefore, it is important to understand the relationship between the phase segregation and the crystalline defects to further improve the performance and stability of the perovskite solar cells (PSCs). The $\mathrm{CsPbI}_{3-x} \mathrm{Br}_{x}$ inorganic perovskites exhibit better structural stability than the hybrid perovskites under electron beams, enabling analysis of the relationship between the phase segregation and the defects' details by advanced electron microscopy techniques [17,21-24]. Furthermore, $\mathrm{CsPbI}_{3-x} \mathrm{Br}_{x}$ inorganic perovskites are more thermally stable than hybrid perovskites; thus, they have attracted increasing amounts of attention for their photovoltaic and light-emitting properties [7,25-33].

In this paper, we attempt to improve the quality of the $\mathrm{CsPbIBr}{ }_{2}$ crystal to suppress the halide segregation to achieve a photo-stable material $[15,18]$. Excess amounts of $\mathrm{PbBr}_{2}$ or CsI were incorporated into the inorganic $\mathrm{Cs} \mathrm{PbIBr}_{2}$, prepared from originally even molar amounts of $\mathrm{PbBr}_{2}$ and CsI. We found that the $\mathrm{PbBr}_{2}$-excess composition favored the formation of $\mathrm{Pb}(\mathrm{I}, \mathrm{Br})_{2}$.dimethyl sulfoxide (DMSO), and quasi-two-dimensional (2D) $\mathrm{CsPb}_{2}(\mathrm{I}, \mathrm{Br})_{5}$. These intermediate phases greatly enhanced the Ostwald ripening, reducing the interface energy and increasing the mass transportation of the constituents for $\mathrm{CsPbIr}_{2}$ crystal growth [34,35]. A significantly larger grain size and a lower defect density were achieved by compositional engineering via the $\mathrm{PbBr}_{2}$-excess composition. Therefore, no halide phase segregation was detected at the GBs nor the perovskite/ $\mathrm{TiO}_{2}$ interfaces, and there was an increased minority carrier lifetime, a reduced $J-V$ hysteresis, and an improved solar-cell performance. In contrast, the CsI-excess did not improve the properties of the $\mathrm{CsPbIBr}$ PSCs in any way.

\section{EXPERIMENTAL SECTION}

\section{Materials}

Unless specified otherwise, all the materials were purchased from either Alfa Aesar or Sigma-Aldrich and used as received. Spiro-OMeTAD (2,20,7,70-tetrakis ( $N, N$-dip-methoxyphenylamine)-9,9-spirobifluorene) was purchased from Luminescence Technology Corp.

\section{Device fabrication}

A dense $\mathrm{TiO}_{2}$ blocking layer was first deposited on a clean fluorine-doped tin oxide (FTO) glass by spray pyrolysis at $450^{\circ} \mathrm{C}$, using a bis(isopropoxide)-bis(acetylacetonate)titanium(IV) solution. After cooling to room temperature, the substrate was cut into smaller pieces of approximately $1 \mathrm{~cm}^{2}$.

A concentration of 0.7 or $1 \mathrm{~mol} \mathrm{~L}^{-1} \mathrm{CsPbIBr}_{2}$ in a DMSO precursor solution was then prepared from CsI and $\mathrm{PbBr}_{2}$, at a molar ratio of $1: 1$ for the stoichiometric, 1.05:1 for the CsI-excess, and 1:1.05 for the $\mathrm{PbBr}_{2}$-excess compositions. A compact $\mathrm{CsPbIBr}_{2}$ film was spin-coated onto a $\mathrm{TiO}_{2}$-coated FTO substrate by the gas-assisted method in which dry argon (Ar) gas at 40 psi ( 1 psi = $6.895 \mathrm{kPa}$ ) was blown over the film's surface for $30 \mathrm{~s}$, once the spinning speed reached $1000 \mathrm{r} \mathrm{min}^{-1}$. The films were then annealed at $320^{\circ} \mathrm{C}$ for $20 \mathrm{~min}$ in a tube furnace with an Ar atmosphere. Subsequently, $25 \mu \mathrm{L}$ of the spiroOMeTAD solution (prepared by dissolving $41.6 \mathrm{mg}$ of spiro-OMeTAD in $0.5 \mathrm{~mL}$ of chlorobenzene and adding $7.5 \mu \mathrm{L}$ of a stock solution of $520 \mathrm{mg} \mathrm{mL}^{-1}$ of lithium bis(trifluoromethylsulphonyl)imide in acetonitrile) and 
$16.9 \mu \mathrm{L}$ of 4-tert-butylpyridine was coated onto the $\mathrm{CsPbIBr}$ film by spin-coating at $3000 \mathrm{r} \mathrm{min}^{-1}$ for $30 \mathrm{~s}$ in a glove box filled with nitrogen. Finally, an $80-\mathrm{nm}$ gold layer was deposited by thermal evaporation to form the complete device.

\section{CL characterization}

CL characterization was performed using an FEI Nova NanoSEM 450 scanning electron microscope (SEM) equipped with a Delmic SPARC CL System. The $\mathrm{Cs} \mathrm{PbIBr}_{2}$ films for CL characterizations were deposited on a typical substrate used for photovoltaic devices [24], consisting of layers of $\mathrm{TiO}_{2}, \mathrm{FTO}$, and glass. Before the CL characterization, the $\mathrm{CsPbIBr}$ films were kept in a dark vacuum chamber for more than $10 \mathrm{~min}$ to avoid unintended light-induced phase segregation. All of the CL mappings were recorded from the previously unexposed regions of the sample, except when specifically indicated. The CL measurements were carried out under electronbeam-accelerating voltages of 2 and $5 \mathrm{kV}$. A fresh crosssection was created by direct mechanical cleaving just before loading the sample into the SEM chamber for cross-sectional CL mapping.

At the electron-beam-acceleration voltage of $2 \mathrm{kV}$, the $\mathrm{CL}$ intensity mapping through the photomultiplier tube (PMT) was obtained with a resolution of $1024 \times 1024$ pixels ( $11 \mathrm{~nm}$ on each side) and a dwell time of $300 \mu \mathrm{s}$ per pixel, while the CL spectral maps were obtained with a dwell time of $200 \mathrm{~ms}$ per pixel. The electron-beam current was fixed at $440 \mathrm{pA}$.

At the electron-beam-acceleration voltage of $5 \mathrm{kV}$, the CL-PMT maps were obtained with a resolution of $1024 \times$ 1024 pixels ( $\sim 11 \mathrm{~nm}$ on each side) and a dwell time of $50 \mu$ s per pixel, while the CL spectral maps were obtained with a dwell time of $10 \mathrm{~ms}$. The electron-beam current was fixed at $799 \mathrm{pA}$.

\section{Photoluminescence}

The photoluminescence (PL) spectra were collected by a confocal microscope system (WITec, alpha 300R) in ambient conditions. The $\mathrm{CsPbIBr}$ samples were excited using a 532-nm laser source. The time-resolved PL (TRPL) decay traces were measured using a time-correlated single photon counting (TCSPC) technique on a Micro Time 200 (Picoquant) microscope, by $470-\mathrm{nm}$ laser excitation at a $1 \mathrm{MHz}$ repetition rate and detection through a bandpass pass filter $(582 \pm 75 \mathrm{~nm})$. The excitation power density was $300 \mathrm{~mW} \mathrm{~cm} \mathrm{~cm}^{-2}$. The PL decay traces measured by the TCSPC were well fitted with a biexponential function:
$I(t)=A_{1} \exp \left(-\frac{t}{\tau_{1}}\right)+A_{2} \exp \left(-\frac{t}{\tau_{2}}\right)$,

where $I(t)$ was the time-dependent PL intensity, $\tau_{1}$ and $\tau_{2}$ were the lifetimes of the fast and the slow decay components, respectively, and $A_{1}$ and $A_{2}$ were the corresponding amplitudes. From this, we defined the effective lifetime as [36]

$\tau_{\text {eff }}=\left(A_{1} \tau_{1}+A_{2} \tau_{2}\right) /\left(A_{1}+A_{2}\right)$.

\section{Solar-cell performance characterizations}

Current-voltage characterization was performed using a solar simulator (Oriel) fitted with a filtered $1000 \mathrm{~W}$ xenon lamp to replicate $\mathrm{AM} 1.5,100 \mathrm{~mW} \mathrm{~cm}^{-2}$ conditions. The illumination of the light source was calibrated using a silicon reference cell (Peccell Technologies) with a color filter to minimize the spectral mismatch between the calibration diode and the PSC. The $J-V$ response was recorded using a Keithley 2400 source meter. The solar cells were masked with a non-reflective metal aperture of $0.16 \mathrm{~cm}^{2}$ that defined the active area of the device. The $J$ $V$ measurements were carried out with a scan rate of $100 \mathrm{mV} \mathrm{s}^{-1}$ from the forward bias to the short-circuit (reverse scan) and from the short-circuit to the forward bias (forward scan). The external quantum efficiency (EQE) measurements were performed using a $150 \mathrm{~W}$ xenon lamp (Oriel) fitted with a monochromator (Cornerstone 260). The EQE photocurrents were recorded under the short-circuit conditions using a Keithley 2400 source meter. The monochromatic photon flux was quantified via a calibrated silicon cell (Peccell Technologies).

\section{Other characterizations}

The perovskite samples for X-ray diffraction (XRD) were prepared on the $\mathrm{TiO}_{2}$-coated FTO-glass substrates and analyzed using a D2 PHASER (Bruker Corp.). Fourier transform infrared (FTIR) spectra were recorded with an Agilent Technologies Cary 630 spectrometer. The $\mathrm{CsPbIBr}$ samples were deposited by spin-coating onto glass substrates and were scratched for analysis.

\section{RESULTS}

\section{Crystal growth versus composition}

Chemical composition engineering has already exhibited a significant influence on crystal growth, defect passivation, and solar-cell performance in hybrid perovskites $[37,38]$. Stoichiometric hybrid organic-inorganic perovskites can be achieved from a non-stoichiometric pre- 
cursor solution since the excess organic cations are removed during annealing due to their volatile nature [38]. In contrast, due to the superior thermal stability of the inorganic components, excess $\mathrm{CsX}(\mathrm{X}=\mathrm{I}, \mathrm{Br})$ or $\mathrm{PbX}_{2}$ are retained after annealing by the formation of secondary phases such as $\mathrm{Cs}_{4} \mathrm{PbX}_{6}$ and $\mathrm{CsPb}_{2} \mathrm{X}_{5}$, according to the phase diagram of $\mathrm{PbBr}_{2}$-CsBr [39]. Compared with the hybrid perovskites, this more complicated phase diagram provides improved prospects for using compositional engineering to control the crystal growth process and, thereby, to improve the generation, transportation, and collection of free carriers, as well as the recombination in inorganic perovskites. Therefore, we first studied the effect of the precursor chemical composition on the $\mathrm{CsPbIBr}{ }_{2}$ crystal growth and the microstructure evolution during thermal annealing. (Hereafter, "CsI-excess" and " $\mathrm{PbBr}_{2}$-excess" refer to excess of $\mathrm{CsI}$ or $\mathrm{PbBr}_{2}$, respectively, being incorporated into originally even molar amounts of $\mathrm{PbBr}_{2}$ and CsI precursor solution.)

The conversion from the precursor to the crystallized $\mathrm{Cs} \mathrm{PbIBr}_{2}$ film was monitored morphologically, compositionally, and crystallographically by SEM, FTIR, and insitu heating XRD, as shown in Fig. 1. All three compositions showed almost identical average grain sizes $(<100 \mathrm{~nm})$, after annealing at $70^{\circ} \mathrm{C}$ for $10 \mathrm{~min}$. The in-situ heating and ex-situ XRD spectra in Fig. 1a and Fig. S1 prove that these small grains were mainly the "black phase" orthorhombic $\mathrm{CsPbIr}_{2}$ perovskite with XRD peaks at $15^{\circ}, 21.2^{\circ}$, and $30.1^{\circ}$, corresponding to the $\{110\}$, $\{200\}$, and $\{220\}$ planes [29]. The FTIR spectra for all three compositions indicated the existence of $\mathrm{Pb}(\mathrm{I}, \mathrm{Br})_{2}$. DMSO, showing a peak at $\sim 900-1000 \mathrm{~cm}^{-1}$ that corresponded to the $\mathrm{S}=\mathrm{O}$ stretching vibration of the $\mathrm{Pb}(\mathrm{I}$, $\mathrm{Br}_{2}$.DMSO adduct, as shown in Fig. 1b [40-42].

As the annealing temperature was increased to $175^{\circ} \mathrm{C}$ and was maintained as such for $5 \mathrm{~min}$, the average grain size of the $\mathrm{CsPbIBr}_{2}$ increased to a few hundred nanometers for all three precursor compositions. The large $\mathrm{CsPbIBr} 2$ crystals were grown at the expense of smaller ones, consistent with Ostwald ripening [34,35] (Ostwald ripening is a phenomenon observed in solid solutions or liquid sols that describes the change of an inhomogeneous structure over time, i.e., small crystals or sol particles dissolve and are redeposited onto larger crystals or sol particles). Ostwald ripening is driven by the reduction in the total surface free energy resulting from the enlarging grain size. It has been reported that DMSO released from the $\mathrm{Pb}(\mathrm{I}, \mathrm{Br})_{2} \cdot \mathrm{DMSO}$ adduct in the $\mathrm{CsPb}(\mathrm{I}$, $\mathrm{Br})_{3}$ precursor film can greatly facilitate mass transport, enhancing the Ostwald ripening and defect annihilation in the $\mathrm{CsPb}(\mathrm{I}, \mathrm{Br})_{3}[43,44]$ through the following reaction: $\mathrm{Pb}(\mathrm{I}, \mathrm{Br})_{2} \cdot \mathrm{DMSO} \rightarrow \mathrm{Pb}(\mathrm{I}, \mathrm{Br})_{2}+\mathrm{DMSO}$.

However, as the annealing time was extended to $20 \mathrm{~min}$ (at $175^{\circ} \mathrm{C}$ ), the crystal growth of the CsI-excess samples almost finished, while the stochiometric and $\mathrm{PbBr}_{2}$-excess samples kept growing. This was consistent with the fact that DMSO had been fully removed in the CsI-excess sample, while traces of DMSO could still be seen in the other two compositions after annealing at $175^{\circ} \mathrm{C}$ for 5 min (Fig. 1b).

After annealing at $175^{\circ} \mathrm{C}$ for $20 \mathrm{~min}$, DMSO had been fully removed from all these three compositions, as suggested in Fig. 1b. Therefore, DMSO-assisted sintering could not explain the further crystal growth of the $\mathrm{CsPbIBr} 2$ in the stochiometric and the $\mathrm{PbBr}_{2}$-excess samples. In the stochiometric and the $\mathrm{PbBr}_{2}$-excess samples, it was evident that the small crystals dispersed at the GBs had gradually merged into the growing $\mathrm{CsPbIBr}_{2}$ large crystals with increasing temperature or time (Fig. 1a). This indicated that the growth of the $\mathrm{CsPbIBr}$ crystals might have been further enhanced by these small crystals after the DMSO were fully evaporated. The CL spectra proved the existence of $\mathrm{Pb}(\mathrm{I}, \mathrm{Br})_{2}$ and $\mathrm{CsPbIBr}_{2}$ in these small crystals, which showed a much lower CL intensity compared with the large $\mathrm{CsPbIBr}_{2}$ crystals in Figs S2 and S3.

As the annealing continued, the residual small crystals migrated together and combined into larger crystals, which showed much darker secondary electron (SE) contrast in the SEM images collected at an acceleration voltage of $2 \mathrm{kV}$ (Fig. 1a). In Fig. 2a, the energy dispersive spectrometer (EDS) results prove that the $\mathrm{CsPb}_{2}(\mathrm{I}, \mathrm{Br})_{5}$ grains (grains labeled as 1-3) showed much darker SE contrast than the $\mathrm{CsPb}(\mathrm{I}, \mathrm{Br})_{3}$ grains (grains labeled as 46). However, as the acceleration voltage for the SEM image increased from 2 to $10 \mathrm{kV}$, the contrast of the $\mathrm{CsPb}_{2}(\mathrm{I}, \mathrm{Br})_{5}$ and $\mathrm{CsPb}(\mathrm{I}, \mathrm{Br})_{3}$ grains became almost the same. Therefore, SEM at the low-acceleration voltage $(2 \mathrm{kV})$ is an effective way to identify the distribution of $\mathrm{CsPb}_{2}(\mathrm{I}, \mathrm{Br})_{5}$ secondary phases. The existence of $\mathrm{CsPb}_{2}(\mathrm{I}$, $\mathrm{Br})_{5}$ was also identified by the in-situ heating XRD with a peak position at $11.3^{\circ}$, corresponding to the $(001)_{t}$ orientation of the tetragonal $\mathrm{CsPb}_{2}(\mathrm{I}, \mathrm{Br})_{5}$ phase [45] (throughout this manuscript, the subscripts " $\mathrm{t}$ " and "o" denote indexing in the tetragonal and orthorhombic phases, respectively). The $\mathrm{CsPb}_{2}(\mathrm{I}, \mathrm{Br})_{5}$ phase was formed due to the following reaction:

$\mathrm{Pb}(\mathrm{I}, \mathrm{Br})_{2}+\mathrm{CsPb}(\mathrm{I}, \mathrm{Br})_{3} \rightarrow \mathrm{CsPb}_{2}(\mathrm{I}, \mathrm{Br})_{5}$.

As the annealing temperature increased to $240^{\circ} \mathrm{C}$, the 

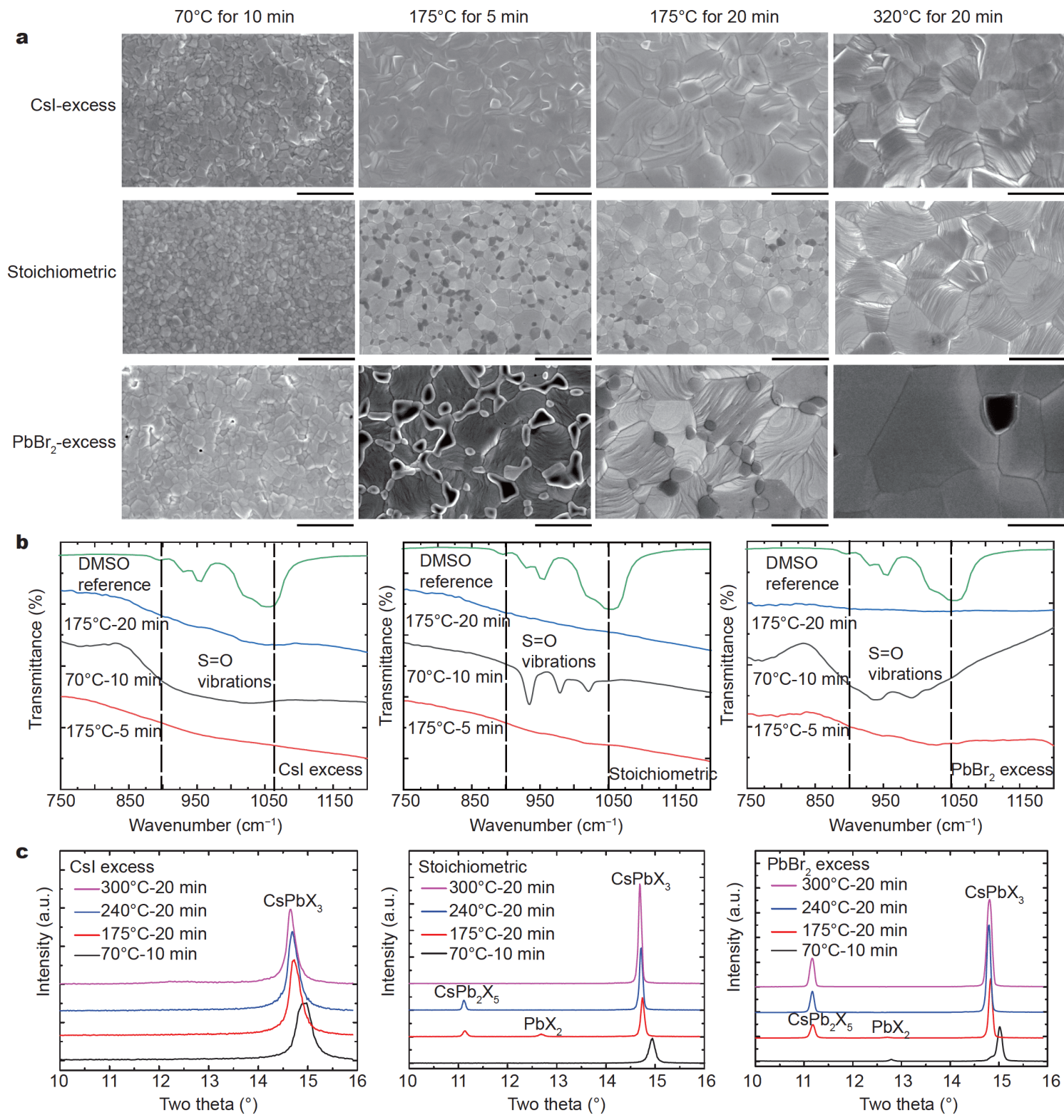

Figure 1 (a) SEM images, (b) FTIR, and (c) in-situ heating XRD of the CsPbIBr 2 thin films with the precursors of stoichiometric, CsI-excess, and $\mathrm{PbBr}_{2}$-excess compositions at elevated annealing temperatures. The FTIR for the DMSO reference in (b) is obtained from reference [42]. The scale bars in the SEM images are $1 \mu \mathrm{m}$. These SEM images are collected with an electron-beam-acceleration voltage of $2 \mathrm{kV}$. The samples for the FTIR are in the form of powder scratched from the deposited $\mathrm{CsPbIBr}_{2}$ films.

$\mathrm{Pb}(\mathrm{I}, \mathrm{Br})_{2}$ was fully converted to the $\mathrm{CsPb}_{2}(\mathrm{I}, \mathrm{Br})_{5}$ phase, as proved by the in-situ heating XRD analysis. However, after annealing at $320^{\circ} \mathrm{C}$ for $20 \mathrm{~min}$, the $\mathrm{CsPb}_{2}(\mathrm{I}, \mathrm{Br})_{5}$ phase in the stochiometric sample completely disappeared in both the SEM and the in-situ heating XRD. In contrast, in the $\mathrm{PbBr}_{2}$-excess samples, the $\mathrm{CsPb}_{2}(\mathrm{I}, \mathrm{Br})_{5}$ phase was still present. From the observation above, it can be seen that the $\mathrm{CsPb}_{2}(\mathrm{I}, \mathrm{Br})_{5}$ and the $\mathrm{CsPb}(\mathrm{I}, \mathrm{Br})_{3}$ were mutually convertible. The small $\mathrm{CsPb}(\mathrm{I}, \mathrm{Br})_{3}$ crystals were first converted to $\mathrm{CsPb}_{2}(\mathrm{I}, \mathrm{Br})_{5}$ when the excess $\mathrm{Pb}(\mathrm{I}, \mathrm{Br})_{2}$ was available. As the annealing temperature further increased, the $\mathrm{CsPb}_{2}(\mathrm{I}, \mathrm{Br})_{5}$ reacted with the remaining $\mathrm{Cs}(\mathrm{I}, \mathrm{Br})$ to form $\mathrm{CsPb}(\mathrm{I}, \mathrm{Br})_{3}$, according to the following reaction:

$\mathrm{CsPb}_{2}(\mathrm{I}, \mathrm{Br})_{5}+\mathrm{Cs}(\mathrm{I}, \mathrm{Br}) \rightarrow 2 \mathrm{CsPb}(\mathrm{I}, \mathrm{Br})_{3}$.

\section{Phase segregation versus composition}

$\mathrm{PL}$ is a sensitive tag, identifying the phase segregation 

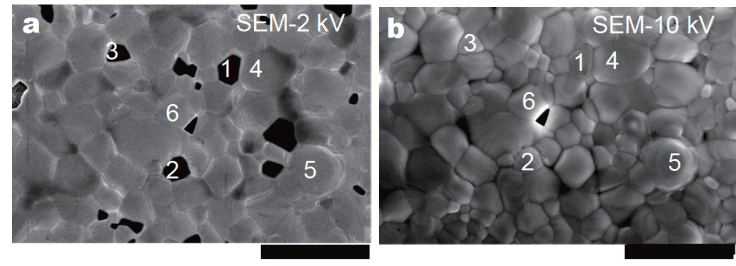

\begin{tabular}{|c|c|c|c|}
\hline \multirow[t]{2}{*}{ Points } & \multicolumn{3}{|c|}{ Molar ratio } \\
\hline & $\mathrm{Pb} / \mathrm{Cs}$ & $(\mathrm{Br}+1) / \mathrm{Pb}$ & $\mathrm{Br} / \mathrm{l}$ \\
\hline 1 & 2.1 & 2.5 & 1.5 \\
\hline 2 & 2.1 & 2.5 & 1.3 \\
\hline 3 & 2.1 & 2.5 & 1.3 \\
\hline 4 & 1.0 & 3.0 & 2.1 \\
\hline 5 & 1.0 & 3.0 & 2.0 \\
\hline 6 & 1.0 & 3.0 & 2.0 \\
\hline $\mathrm{CsPb}_{2} \mathrm{X}_{5}$ & $2.1 \pm 0.0$ & $2.5 \pm 0.1$ & $1.3 \pm 0.0$ \\
\hline $\mathrm{CsPblBr}_{2}$ & $1.0 \pm 0.0$ & $3.0 \pm 0.0$ & $2.0 \pm 0.0$ \\
\hline
\end{tabular}
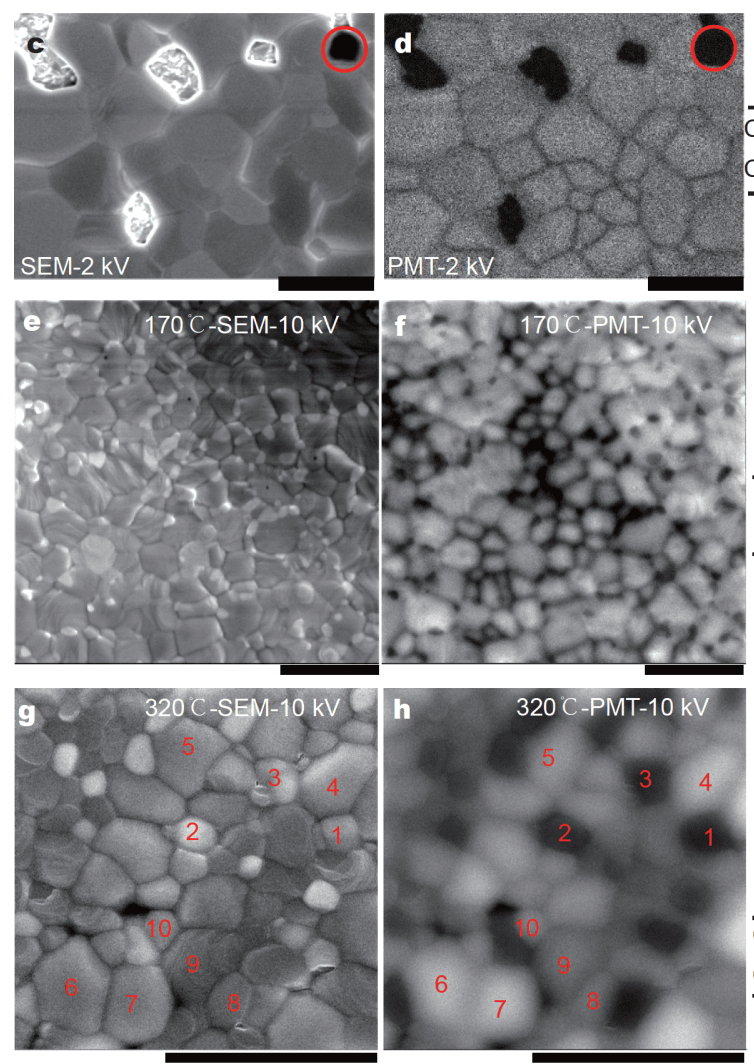

\begin{tabular}{cccc}
\hline j & \multicolumn{3}{c}{ Molar ratio } \\
\hline Points & $\mathrm{Pb} / \mathrm{Cs}$ & $(\mathrm{Br}+\mathrm{I}) / \mathrm{Pb}$ & $\mathrm{Br} / \mathrm{l}$ \\
\hline 1 & 1.7 & 2.5 & 1.5 \\
2 & 2 & 2.5 & 1.7 \\
3 & 2 & 2.4 & 1.5 \\
4 & 1.0 & 3.0 & 2.1 \\
5 & 1.0 & 3.0 & 2.0 \\
6 & 1.0 & 3.0 & 2.0 \\
7 & 1.1 & 2.9 & 2.1 \\
8 & 1.0 & 3.1 & 1.9 \\
9 & 1.0 & 3.1 & 1.9 \\
10 & 1.0 & 2.9 & 1.9 \\
\hline $\mathrm{CsPb}_{2} \mathrm{X}_{5}$ & $1.9 \pm 0.2$ & $2.5 \pm 0.1$ & $1.6 \pm 0.1$ \\
$\mathrm{CsPblBr}_{2}$ & $1.0 \pm 0.0$ & $3.0 \pm 0.1$ & $2.0 \pm 0.1$ \\
\hline & & &
\end{tabular}

Figure 2 (a-d) Investigation of the chemical composition of the photo-inactive phase in the $\mathrm{PbBr}_{2}$-excess $\mathrm{CsPbIBr}_{2}$ film. (a, b) SEM images with the same region in the $\mathrm{PbBr}_{2}$-excess CsPbIBr${ }_{2}$ film with the electron-beam-acceleration voltages of 2 and $10 \mathrm{kV}$, respectively. (c, d) SEM image and CLPMT map for the $\mathrm{PbBr}_{2}$-excess CsPbIBr${ }_{2}$ film at the electron-beam-acceleration voltage of $2 \mathrm{kV}$, respectively. (e-h) Investigation of the photo-inactive phase evolution during the crystal growth of the $\mathrm{PbBr}_{2}$-excess $\mathrm{CsPbIBr}_{2}$ film at an annealing temperature of $170^{\circ} \mathrm{C}$ for $5 \mathrm{~min}\left(\mathrm{e}, \mathrm{f}\right.$ ), and $320^{\circ} \mathrm{C}$ for $20 \mathrm{~min}$ (g, h). (f, h) CL-PMT mapping corresponding to the SEM images of (f) and (g), respectively. (i, j) Chemical compositions obtained by EDS corresponding to the numbered points in $(\mathrm{a}, \mathrm{b})$ and $(\mathrm{g}, \mathrm{h})$, respectively. The scale bars are $3 \mu \mathrm{m}$.

with the formation of a strong red-shifted PL peak that was first reported by Hoke et al. [6]. Light-induced phase segregation was observed in the stoichiometric and CsIexcess $\mathrm{CsPbIBr}$ samples, in which the PL spectra of these perovskites developed a new, red-shifted peak at 640-680 nm under constant 1-sun illumination in $100 \mathrm{~s}$, as shown in Fig. S4a. This suggested that the CsPbIBr segregated into two phases: an iodide-rich minority domain $\left(\mathrm{CsPbI}_{1+x} \mathrm{Br}_{2-x}\right)$ and a bromide-rich majority domain $\left(\mathrm{CsPbI}_{1-x} \mathrm{Br}_{2+x}\right)$ [31]. In contrast, the $\mathrm{PbBr}_{2}$-excess sample showed much better stability under continuous laser exposure with the single PL peak remaining at $\sim 585 \mathrm{~nm}$, corresponding to the original $\mathrm{CsPbIBr}_{2}$ phase; this is also suggested by the plane view CL spectra maps in Fig. S5 (see Supplementary Discussion for the detailed analysis).

Cross-sectional CL mapping was employed to further reveal the influence of the $\mathrm{TiO}_{2}$ /perovskite interfacial defects on the phase segregation; this is not a well-studied phenomenon. We present CL maps of cross-sections of the $\mathrm{CsPbIBr}{ }_{2}$ films with stoichiometric, CsI-excess, and $\mathrm{PbBr}_{2}$-excess precursor compositions, as shown in Fig. 3. The layered structure sequences in all these cross-sectional figures are the same as Fig. 3a (layers from top to bottom: $\mathrm{CsPbIBr} / 2 / \mathrm{c}-\mathrm{TiO}_{2} /$ transparent conducting oxide (TCO)). In both the stoichiometric and CsI-excess films, 

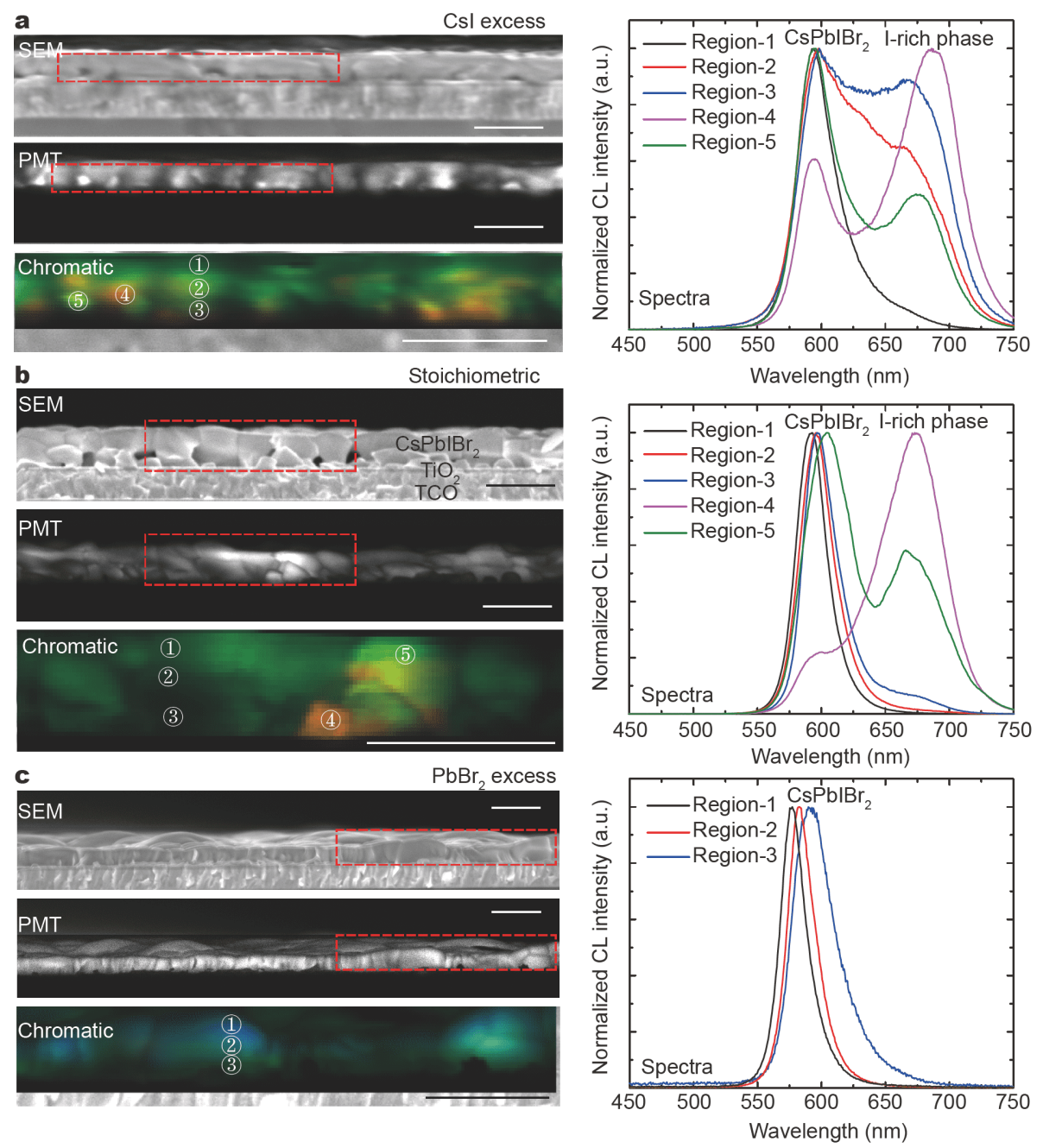

Figure 3 The CL-PMT intensity mapping (labeled as PMT) and spectrum mapping (labeled as chromatic) used to investigate the phase segregation in the cross-section of the $\mathrm{CsPlBr}_{2}$ film (a) CsI-excess, (b) at stoichiometric, and (c) $\mathrm{PbBr}_{2}$-excess compositions, using an electron-beam-acceleration voltage of $5 \mathrm{kV}$. All the scale bars are $1 \mu \mathrm{m}$. The CL spectra corresponding to the circled region labeled in the CL spectrum are shown in the right figure of each composition. The color code in the CL spectral map indicates the wavelength of the emitted light, with the red regions having a longer emitted light wavelength than the green regions and the brightness indicating the emitted light intensity.

phase segregation took place not only at the film's surface but also throughout the whole depth of the film. More importantly, the iodide-rich phases tended to segregate at the $\mathrm{TiO}_{2} / \mathrm{CsPbIBr}_{2}$ interface, which could only be directly observed by the CL cross-sectional mapping. Even within the same single crystal, the emission from the iodide-rich phase increased from the film's surface to the $\mathrm{TiO}_{2} /$ $\mathrm{CsPbIBr}_{2}$ interface (from Region 1 to Region 3 in Fig. 3a, c), indicating that an increasing amount of the iodide-rich phase was segregated at the interface. The $\mathrm{CsPbIBr}$ with an excess of $\mathrm{PbBr}_{2}$ showed a more uniform emission-peak wavelength, indicating that the phase segregation was inhibited across the depth of the film, as shown in Fig. 3c. However, the CL spectra from a series of regions adjacent to the $\mathrm{TiO}_{2} / \mathrm{CsPbIBr}_{2}$ interface showed the CL peak position slightly shifting to longer wavelengths, suggesting a slightly higher iodine concentration at the interface. To summarize, the iodide-rich phases tended to segregate at the defects, such as the GBs and the heterojunction interfaces. Phase segregation can be greatly inhibited by adjusting the $\mathrm{Cs} \mathrm{PbIBr}_{2}$ precursor solution composition with a slight $\mathrm{PbBr}_{2}$ excess.

\section{$J-V$ hysteresis versus composition}

It was also observed that the precursor chemical composition had a significant influence on the performance of the $\mathrm{CsPbIBr}_{2}$ inorganic PSCs, as shown in Fig. 4. In the $\mathrm{CsPbIBr}_{2}$ prepared with CsI-excess, a power conversion 

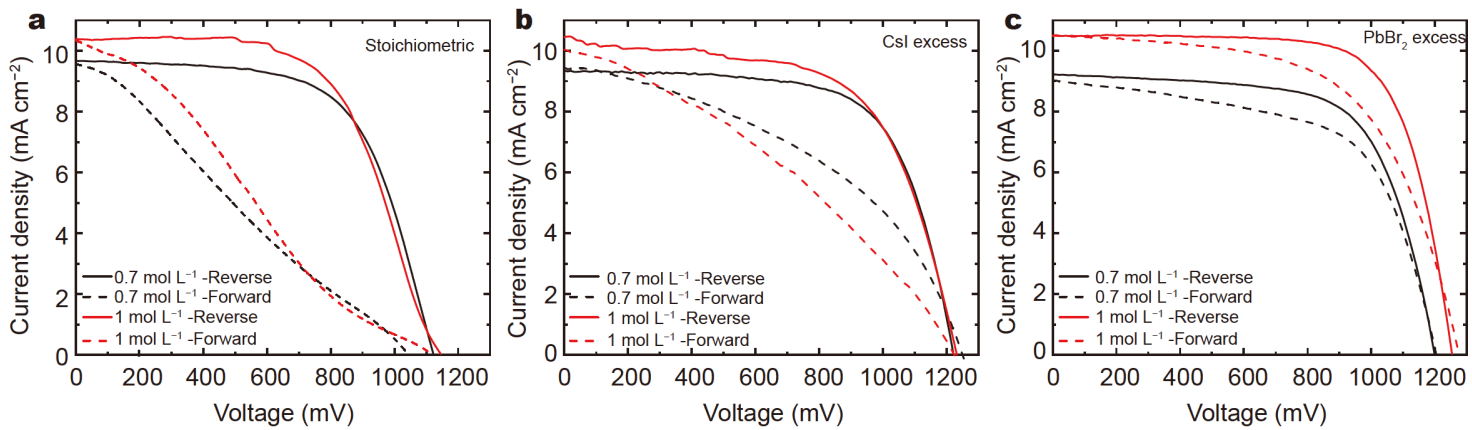

Figure $4 \mathrm{~J}$-V curves of $\mathrm{CsPbIBr}_{2}$ inorganic PSCs with the precursors of (a) stoichiometric, (b) at CsI-excess, and (c) at $\mathrm{PbBr}_{2}$-excess compositions. The $J-V$ curves were recorded under different scan conditions (reverse, from forward bias to short-circuit, and forward, from short-circuit to forward bias; scan speed, $100 \mathrm{mV} \mathrm{s}^{-1}$ ). The precursor solution's molar concentrations and compositions are shown in the legend of each figure.

efficiency (PCE) of $7.70 \%$ was achieved in a reverse $J-V$ scan, while a much-reduced efficiency of $4.02 \%$ was derived when scanned from the short-circuit to the forward bias, as shown in Table 1. It was clear that the CsPbIBr PSCs prepared with CsI-excess exhibited a strong hysteresis in the $J-V$ scan measurements, with a hysteresis index (HI) of 33\%, as defined by Equation (1) [46]:

$\mathrm{HI}=\frac{\mathrm{PCE}_{\text {reverse }}-\mathrm{PCE}_{\text {forward }}}{\mathrm{PCE} \mathrm{E}_{\text {reverse }}} \times 100 \%$.

However, the $\mathrm{CsPbIBr}$ PSC prepared with $\mathrm{PbBr}_{2}$-excess exhibited a much lower HI of $10.9 \%$, with a PCE of $7.35 \%$ from the reverse $J-V$ scan and $6.55 \%$ from the forward $J-V$ scan. The average $\mathrm{HI}$ of the $\mathrm{PbBr}_{2}$-excess PSCs (19.2\%) was also much lower than that of the solar cells prepared with stoichiometric (46.5\%) and with the CsI-excess (42.7\%) precursor compositions, as shown in
Table S1. Therefore, the hysteresis of the inorganic $\mathrm{CsPbIBr}{ }_{2}$ PSCs was greatly reduced by the introduction of the $\mathrm{PbBr}_{2}$-excess.

By increasing the precursor's molar concentration from 0.7 to $1 \mathrm{~mol} \mathrm{~L}^{-1}$, the film thickness increased from $\sim 300$ to $\sim 380 \mathrm{~nm}$, which resulted in the average short-circuit current density $\left(J_{\mathrm{SC}}\right)$ of all three compositions increasing from $\sim 9$ to $\sim 10 \mathrm{~mA} \mathrm{~cm}^{-2}$, as shown in Table 1. Meanwhile, the average open circuit voltage $\left(V_{\mathrm{OC}}\right)$ also increased, stemming from a reduced pin-hole density, as shown in Fig. S6. However, the precursor composition did not influence the $J-V$ hysteresis of the PSCs.

Consequently, the PSC with the precursor's molar concentration of $1 \mathrm{~mol} \mathrm{~L}^{-1}$ and the composition of $\mathrm{PbBr}_{2}$ excess showed the highest PCE of $9.37 \%$ in a reverse $J-V$ scan, while a PCE of $7.94 \%$ was measured from the for-

Table 1 The photovoltaic device parameters of the best-performing $\mathrm{CsPbIBr}_{2}$ solar cells with the precursor concentrations of 0.7 and $1 \mathrm{~mol} \mathrm{~L} \mathrm{~L}^{-1}$ and the compositions of the stoichiometric, CsI-excess, and $\mathrm{PbBr}_{2}$-excess

\begin{tabular}{|c|c|c|c|c|c|c|}
\hline $\begin{array}{c}\text { Concentration } \\
\text { composition }\end{array}$ & $\begin{array}{c}J-V \text { scanning } \\
\text { direction }\end{array}$ & $V_{\mathrm{OC}}(\mathrm{mV})$ & $J_{\mathrm{SC}}\left(\mathrm{mA} \mathrm{cm}^{-2}\right)$ & $\begin{array}{l}\text { Fill } \\
\text { factor }\end{array}$ & PCE (\%) & HI (\%) \\
\hline \multirow{2}{*}{$\begin{array}{l}0.7 \mathrm{~mol} \mathrm{~L}^{-1} \\
\text { Stoichiometric }\end{array}$} & Reverse & 1123 & 9.67 & 0.628 & 6.82 & \multirow{2}{*}{63.78} \\
\hline & Forward & 1044 & 9.56 & 0.247 & 2.47 & \\
\hline \multirow{2}{*}{$\begin{array}{l}1 \mathrm{~mol} \mathrm{~L}^{-1} \\
\text { Stoichiometric }\end{array}$} & Reverse & 1148 & 10.39 & 0.598 & 7.13 & \multirow{2}{*}{57.78} \\
\hline & Forward & 1119 & 10.34 & 0.26 & 3.01 & \\
\hline \multirow{2}{*}{$\begin{array}{l}0.7 \mathrm{~mol} \mathrm{~L}^{-1} \\
\text { CsI-excess }\end{array}$} & Reverse & 1222 & 9.43 & 0.668 & 7.7 & \multirow{2}{*}{33.3} \\
\hline & Forward & 1250 & 9.45 & 0.434 & 5.13 & \\
\hline \multirow{2}{*}{$\begin{array}{l}1 \mathrm{~mol} \mathrm{~L}^{-1} \\
\text { CsI-excess }\end{array}$} & Reverse & 1233 & 10.45 & 0.608 & 7.83 & \multirow{2}{*}{44.83} \\
\hline & Forward & 1224 & 10.04 & 0.352 & 4.32 & \\
\hline \multirow{2}{*}{$\begin{array}{l}0.7 \mathrm{~mol} \mathrm{~L}^{-1} \\
\mathrm{PbBr}_{2} \text {-excess }\end{array}$} & Reverse & 1199 & 9.22 & 0.665 & 7.35 & \multirow{2}{*}{10.9} \\
\hline & Forward & 1205 & 9.02 & 0.603 & 6.55 & \\
\hline \multirow{2}{*}{$\begin{array}{c}1 \mathrm{~mol} \mathrm{~L}^{-1} \\
\mathrm{PbBr}_{2} \text {-excess }\end{array}$} & Reverse & 1254 & 10.5 & 0.712 & 9.37 & \multirow{2}{*}{15.3} \\
\hline & Forward & 1276 & 10.48 & 0.594 & 7.94 & \\
\hline
\end{tabular}


ward $J-V$ scan, as seen in Table 1, resulting in a stabilized PCE of $8.48 \%$, as shown in Fig. S7a. It also showed a very broad EQE plateau of over $90 \%$ between 400 and $570 \mathrm{~nm}$, as shown in Fig. S7b. The $J_{\mathrm{SC}}$ value obtained by integrating the overall $\mathrm{EQE}$ agreed well with that seen in the $J-V$ curve.

\section{DISCUSSION}

From the above results, it is clear that a higher $\mathrm{PbBr}_{2}$ :CsI ratio is advantageous for the formation of $\mathrm{Pb}(\mathrm{I}, \mathrm{Br})_{2}$. DMSO and $\mathrm{CsPb}_{2}(\mathrm{I}, \mathrm{Br})_{5}$ intermediate phases, greatly enhancing the Ostwald ripening of $\mathrm{CsPb}(\mathrm{I}, \mathrm{Br})_{3}$ [47]. Consequently, the average grain sizes of the stoichiometric, $\mathrm{PbBr}_{2}$-excess, and CsI-excess compositions were $\sim 0.6, \sim 0.3$, and $\sim 1.5 \mu \mathrm{m}$, respectively. The intermediatephase-enhanced Ostwald ripening of the $\mathrm{CsPb}(\mathrm{I}, \mathrm{Br})_{3}$ could be divided into two phases.

At the low temperature $\left(\leq 175^{\circ} \mathrm{C}\right)$, the Ostwald ripening of the $\mathrm{CsPb}(\mathrm{I}, \mathrm{Br})_{3}$ was dominantly accelerated by the $\mathrm{Pb}(\mathrm{I}, \mathrm{Br})_{2}$.DMSO adduct that was formed as a result of the coordination of the Lewis acid $\mathrm{Pb}(\mathrm{I}, \mathrm{Br})_{2}$ and the Lewis bases DMSO with lone-pair electrons [48]. However, the iodine atom in the CsI contained lone-pair electrons that were ready to couple with the $\mathrm{Pb}(\mathrm{I}, \mathrm{Br})_{2}$ by the formation of a more thermally stable $\mathrm{CsPbIBr}$ phase than the $\mathrm{Pb}(\mathrm{I}, \mathrm{Br})_{2}$.DMSO adduct [49]. Therefore, increasing the $\mathrm{PbBr}_{2}$ :CsI ratio in the precursor solution resulted in the formation of a larger amount of $\mathrm{Pb}(\mathrm{I}$, $\mathrm{Br})_{2} \cdot \mathrm{DMSO}$ adduct, which retarded the release of DMSO. With a higher $\mathrm{PbBr}_{2}$ : CsI ratio, the $\mathrm{CsPbIBr} \mathrm{P}_{2}$ crystal growth and defect annihilation period were greatly elongated, and a significantly larger $\mathrm{CsPbIB}_{2}$ grain size could be achieved by the trace amount of DMSO released at $175^{\circ} \mathrm{C}$.

At the high temperature $\left(>175^{\circ} \mathrm{C}\right)$, all the DMSO had been fully removed, and the crystal growth of the $\mathrm{Cs} \mathrm{PbIBr}_{2}$ was further assisted by the $\mathrm{CsPb}_{2}(\mathrm{I}, \mathrm{Br})_{5}$ intermediate phase. The crystal growth of the $\mathrm{CsPb}_{2}(\mathrm{I}, \mathrm{Br})_{5}$ tended to extend onto the substrate's surface, which resulted from its 2D structure composed of $\mathrm{Cs}^{+}$cations sandwiched between the $\mathrm{Pb}_{2} \mathrm{Br}_{5}{ }^{-}$layers, as shown in Fig. 5h [50]. The $\mathrm{CsPb}_{2}(\mathrm{I}, \mathrm{Br})_{5}$ exhibited anisotropic 2D growth with the $\mathrm{Pb}_{2} \mathrm{Br}_{5}{ }^{-}$layers parallel to the substrate's surface with the $001_{\mathrm{t}}$ direction normal to the substrate [51]. Therefore, the $\mathrm{CsPb}_{2}(\mathrm{I}, \mathrm{Br})_{5}$ phases in the stochiometric and $\mathrm{PbBr}_{2}$-excess samples showed a preferred orientation at $001_{\mathrm{t}}$, as was shown in both the in-situ XRD and the selective area electron diffraction (SAED) pattern in Figs $1 \mathrm{c}$ and $5 \mathrm{~d}$. However, the tetragonal $\mathrm{CsPb}_{2}(\mathrm{I}, \mathrm{Br})_{5}$ at the $001_{\mathrm{t}}$ direction and the orthorhombic $\mathrm{CsPb}(\mathrm{I}, \mathrm{Br})_{3}$ at the $110_{0}$ direction exhibited greater structural similarity than both the experimental and theoretical simulations, as shown in Fig. 5a-g. In particular, these two phases shared almost identical crystal structures during annealing at $320^{\circ} \mathrm{C}$ since all the circulated spots completely disappeared when the orthorhombic $110_{0}$-oriented $\mathrm{CsPbIBr}_{2}$ phase converted to a tetragonal or cubic structure [52]. The Ostwald ripening of the $110_{\mathrm{o}}$-oriented $\mathrm{CsPbIB}_{2}$ phase was greatly enhanced by means of a quasi-2D $001_{\mathrm{t}}$-oriented $\mathrm{CsPb}_{2}(\mathrm{I}, \mathrm{Br})_{5}$ intermediate phase to achieve a large lateral grain size. Consequently, the $\mathrm{CsPbIBr}{ }_{2}$ exhibited a preferred- $110_{0}$ orientation, as shown in both the XRD and the SAED patterns in Figs 1c and $5 \mathrm{~d}$, respectively.

Therefore, the intermediate phases introduced by the $\mathrm{PbBr}_{2}$-excess composition greatly enhanced the Ostwald ripening of the CsPbIBr 2 , facilitating the crystal growth and defect annihilation. Therefore, the halide segregation was eliminated, the minority carrier lifetime was improved (Fig. S4b and Table S2), and the $J-V$ hysteresis of the $\mathrm{CsPbIBr}{ }_{2}$ PSC was reduced.

However, by further increasing the $\mathrm{PbBr}_{2}$ :CsI ratio from 1.05 to 1.2, an average $\mathrm{CsPbIr}_{2}$ grain size of $\sim 3 \mu \mathrm{m}$ was achieved with a $20 \%$ excess of $\mathrm{PbBr}_{2}$ in the precursor solution, as shown in Fig. S8b. However, it also introduced an increasing amount of $\mathrm{CsPb}_{2}(\mathrm{I}, \mathrm{Br})_{5}$, which was photo-inactive with no $\mathrm{CL}$ emission, as shown in Fig. $2 \mathrm{~g}$, h. This result is consistent with the findings of the work by Dursun et al. [50] that intrinsic $\mathrm{CsPb}_{2} \mathrm{Br}_{5}$ is an indirect bandgap material that does not exhibit an appreciable intrinsic PL. Therefore, further increasing the $\mathrm{PbBr}_{2}$ :CsI ratio leads to a decrease in the short-circuit current density of the solar cells, as shown in Fig. S8d.

\section{CONCLUSIONS}

In conclusion, we have demonstrated that the perovskite precursor chemical composition plays an important role in enhancing the crystal growth, reducing the defects, and mitigating the segregation of halides, as well as the $\mathrm{J}-\mathrm{V}$ hysteresis of inorganic CsPbIBr ${ }_{2}$ PSCs. Adding an excess of $\mathrm{PbBr}_{2}$ to the $\mathrm{Cs} \mathrm{PbIBr}_{2}$ precursor solution was found to be beneficial in reducing the GB density, increasing the minority carrier's lifetime, and finally, eliminating segregation and reducing the $J-V$ hysteresis. Preparing the precursor solution at stoichiometric or with CsI-excess composition resulted in the opposite effects. These results directly prove that the phase segregation and the $J-V$ hysteresis resulted from the trap states in the perovskite layer, which can be greatly reduced by controlling the $\mathrm{Cs} \mathrm{PbIBr}_{2}$ crystal growth process. The higher $\mathrm{PbBr}_{2}$ :CsI 

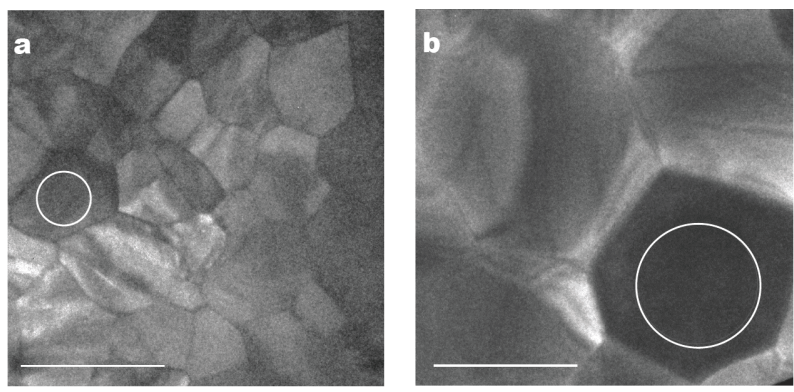

h
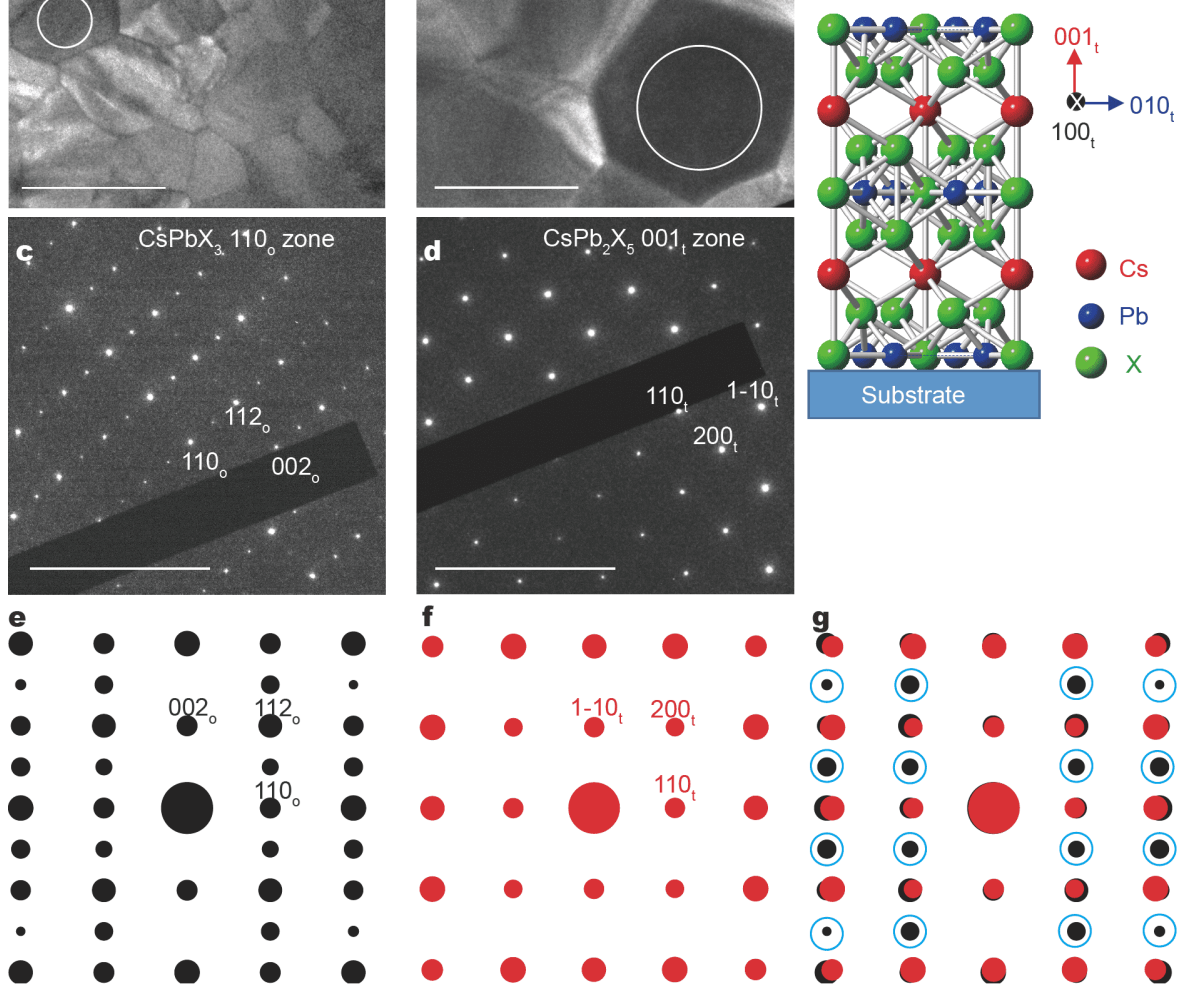

Figure 5 (a, b) Bright field TEM images of the $\mathrm{CsPbIBr}_{2}$ and $\mathrm{CsPb}_{2}(\mathrm{I}, \mathrm{Br})_{5}$ grains in the $\mathrm{PbBr}_{2}$-excess film. (c, d) The experimental SAED patterns taken from the circled regions in $(\mathrm{a}, \mathrm{b})$, respectively. $(\mathrm{e}, \mathrm{f})$ The calculated SAED patterns of $\mathrm{CsPbBr}_{3}$ at the $110_{\mathrm{o}}$ zone axis and the $\mathrm{CsPb}_{2} \mathrm{Br}_{5}$ at $001_{\mathrm{t}}$ zone axis, respectively. ( $\mathrm{g}$ ) The calculated pattern from the overlap of (e) and (f). The circulated spots in ( $\mathrm{g}$ ) will disappear when $\mathrm{CsPbBr} \mathrm{B}_{3}$ is converted from the orthorhombic to the tetragonal and the cubic phases. (h) The atomic model for the $\mathrm{CsPb}_{2} \mathrm{X}_{5}(\mathrm{X}=\mathrm{I}$ and $\mathrm{Br})$ preferentially growing at the $001_{t}$ direction normal to the substrate. The scale bars are: (d, e) $500 \mathrm{~nm}$, and (f, g) $2.5 \mathrm{~nm}^{-1}$.

ratio benefited the formation of the $\mathrm{Pb}(\mathrm{I}, \mathrm{Br})_{2} \cdot \mathrm{DMSO}$ and the quasi-2D $\mathrm{CsPb}_{2}(\mathrm{I}, \mathrm{Br})_{5}$ intermediate phases, which greatly enhanced the Ostwald ripening, and thus improved the crystallinity of the $\mathrm{CsPIBr}_{2}$ photo absorber. Due to the similarity in the crystal structure, these results obtained from the inorganic $\mathrm{CsPbIBr}$ 2 perovskite could provide guidance for the understanding and the removal of some of the issues concerning phase segregation and hysteresis in organic-inorganic mixed halide hybrid perovskites.

Received 10 January 2021; accepted 4 March 2021; published online 1 June 2021

1 Al-Ashouri A, Köhnen E, Li B, et al. Monolithic perovskite/silicon tandem solar cell with $>29 \%$ efficiency by enhanced hole extraction. Science, 2020, 370: 1300-1309

2 Zuo L, Shi X, Fu W, et al. Highly efficient semitransparent solar cells with selective absorption and tandem architecture. Adv Ma- ter, 2019, 31: 1901683

3 Quan LN, García de Arquer FP, Sabatini RP, et al. Perovskites for light emission. Adv Mater, 2018, 30: 1801996

4 Shi B, Duan L, Zhao Y, et al. Semitransparent perovskite solar cells: From materials and devices to applications. Adv Mater, 2020, 32: 1806474

5 Yang TCJ, Fiala P, Jeangros Q, et al. High-bandgap perovskite materials for multijunction solar cells. Joule, 2018, 2: 1421-1436

6 Hoke ET, Slotcavage DJ, Dohner ER, et al. Reversible photoinduced trap formation in mixed-halide hybrid perovskites for photovoltaics. Chem Sci, 2015, 6: 613-617

7 Beal RE, Slotcavage DJ, Leijtens T, et al. Cesium lead halide perovskites with improved stability for tandem solar cells. J Phys Chem Lett, 2016, 7: 746-751

8 Li W, Rothmann MU, Liu A, et al. Phase segregation enhanced ion movement in efficient inorganic $\mathrm{CsPbIBr}_{2}$ solar cells. Adv Energy Mater, 2017, 7: 1700946

9 Braly IL, Stoddard RJ, Rajagopal A, et al. Current-induced phase segregation in mixed halide hybrid perovskites and its impact on two-terminal tandem solar cell design. ACS Energy Lett, 2017, 2: 1841-1847 
10 Kim HP, Kim J, Kim BS, et al. High-efficiency, blue, green, and near-infrared light-emitting diodes based on triple cation perovskite. Adv Opt Mater, 2017, 5: 1600920

11 Duong T, Mulmudi HK, Wu YL, et al. Light and electrically induced phase segregation and its impact on the stability of quadruple cation high bandgap perovskite solar cells. ACS Appl Mater Interfaces, 2017, 9: 26859-26866

12 Shao Y, Fang Y, Li T, et al. Grain boundary dominated ion migration in polycrystalline organic-inorganic halide perovskite films. Energy Environ Sci, 2016, 9: 1752-1759

13 Wei J, Zhao Y, Li H, et al. Hysteresis analysis based on the ferroelectric effect in hybrid perovskite solar cells. J Phys Chem Lett, 2014, 5: 3937-3945

14 Seol D, Jeong A, Han $\mathrm{MH}$, et al. Origin of hysteresis in $\mathrm{CH}_{3} \mathrm{NH}_{3}$ $\mathrm{PbI}_{3}$ perovskite thin films. Adv Funct Mater, 2017, 27: 1701924

15 Rehman W, McMeekin DP, Patel JB, et al. Photovoltaic mixedcation lead mixed-halide perovskites: Links between crystallinity, photo-stability and electronic properties. Energy Environ Sci, 2017, 10: $361-369$

16 Yuan Y, Wang Q, Huang J. Ion migration in hybrid perovskite solar cells. In: Park NG, Grätzel M, Miyasaka T (eds.). OrganicInorganic Halide Perovskite Photovoltaics. Cham: Springer, 2016: 137-162

17 Barker AJ, Sadhanala A, Deschler F, et al. Defect-assisted photoinduced halide segregation in mixed-halide perovskite thin films. ACS Energy Lett, 2017, 2: 1416-1424

18 Knight AJ, Wright AD, Patel JB, et al. Electronic traps and phase segregation in lead mixed-halide perovskite. ACS Energy Lett, 2019, 4: 75-84

19 Ruth A, Brennan MC, Draguta S, et al. Vacancy-mediated anion photosegregation kinetics in mixed halide hybrid perovskites: Coupled kinetic Monte Carlo and optical measurements. ACS Energy Lett, 2018, 3: 2321-2328

20 Samu GF, Janáky C, Kamat PV. A victim of halide ion segregation. How light soaking affects solar cell performance of mixed halide lead perovskites. ACS Energy Lett, 2017, 2: 1860-1861

21 Milosavljević AR, Huang W, Sadhu S, et al. Low-energy electroninduced transformations in organolead halide perovskite. Angew Chem Int Ed, 2016, 55: 10083-10087

22 Klein-Kedem N, Cahen D, Hodes G. Effects of light and electron beam irradiation on halide perovskites and their solar cells. Acc Chem Res, 2016, 49: 347-354

23 Yuan H, Debroye E, Janssen K, et al. Degradation of methylammonium lead iodide perovskite structures through light and electron beam driven ion migration. J Phys Chem Lett, 2016, 7: 561-566

24 Bischak CG, Sanehira EM, Precht JT, et al. Heterogeneous charge carrier dynamics in organic-inorganic hybrid materials: Nanoscale lateral and depth-dependent variation of recombination rates in methylammonium lead halide perovskite thin films. Nano Lett, 2015, 15: 4799-4807

25 Liang J, Wang C, Wang Y, et al. All-inorganic perovskite solar cells. J Am Chem Soc, 2016, 138: 15829-15832

26 Marshall KP, Walker M, Walton RI, et al. Enhanced stability and efficiency in hole-transport-layer-free $\mathrm{CsSnI}_{3}$ perovskite photovoltaics. Nat Energy, 2016, 1: 16178

$27 \mathrm{Fu} \mathrm{Y,} \mathrm{Zhu} \mathrm{H,} \mathrm{Stoumpos} \mathrm{CC,} \mathrm{et} \mathrm{al.} \mathrm{Broad} \mathrm{wavelength} \mathrm{tunable} \mathrm{robust}$ lasing from single-crystal nanowires of cesium lead halide perovskites $\left(\mathrm{CsPbX}_{3}, \mathrm{X}=\mathrm{Cl}, \mathrm{Br}, \mathrm{I}\right)$. ACS Nano, 2016, 10: 7963-7972 28 Kulbak M, Cahen D, Hodes G. How important is the organic part of lead halide perovskite photovoltaic cells? Efficient $\mathrm{CsPbr}_{3}$ cells. J Phys Chem Lett, 2015, 6: 2452-2456

29 Ma Q, Huang S, Wen X, et al. Hole transport layer free inorganic $\mathrm{CsPbIBr}$ 2 perovskite solar cell by dual source thermal evaporation. Adv Energy Mater, 2016, 6: 1502202

30 Ripolles TS, Nishinaka K, Ogomi Y, et al. Efficiency enhancement by changing perovskite crystal phase and adding a charge extraction interlayer in organic amine free-perovskite solar cells based on cesium. Sol Energy Mater Sol Cells, 2016, 144: 532-536

31 Sutton RJ, Eperon GE, Miranda L, et al. Bandgap-tunable cesium lead halide perovskites with high thermal stability for efficient solar cells. Adv Energy Mater, 2016, 6: 1502458

32 Eperon GE, Paternò GM, Sutton RJ, et al. Inorganic caesium lead iodide perovskite solar cells. J Mater Chem A, 2015, 3: 1968819695

33 Swarnkar A, Marshall AR, Sanehira EM, et al. Quantum dotinduced phase stabilization of $\alpha-\mathrm{CsPI}_{3}$ perovskite for high-efficiency photovoltaics. Science, 2016, 354: 92-95

34 Varlamov S, Dore J, Evans R, et al. Polycrystalline silicon on glass thin-film solar cells: A transition from solid-phase to liquid-phase crystallised silicon. Sol Energy Mater Sol Cells, 2013, 119: 246-255

35 Shen Z, Zhao Z, Peng H, et al. Formation of tough interlocking microstructures in silicon nitride ceramics by dynamic ripening. Nature, 2002, 417: 266-269

36 Chen W, Wen X, Latzel M, et al. Nanoscale characterization of carrier dynamic and surface passivation in InGaN/GaN multiple quantum wells on GaN nanorods. ACS Appl Mater Interfaces, 2016, 8: 31887-31893

37 Jeon NJ, Noh JH, Yang WS, et al. Compositional engineering of perovskite materials for high-performance solar cells. Nature, 2015, 517: 476-480

38 Moore DT, Sai H, Tan KW, et al. Crystallization kinetics of organic-inorganic trihalide perovskites and the role of the lead anion in crystal growth. J Am Chem Soc, 2015, 137: 2350-2358

39 Cola M, Massarotti V, Riccardi R, et al. Binary systems formed by lead bromide with ( $\mathrm{Li}, \mathrm{Na}, \mathrm{K}, \mathrm{Rb}, \mathrm{Cs}$ and $\mathrm{Tl}) \mathrm{Br}$ : A DTA and diffractometric study. Z für Naturforschung A, 1971, 26: 13281332

40 Yang WS, Noh JH, Jeon NJ, et al. High-performance photovoltaic perovskite layers fabricated through intramolecular exchange. Science, 2015, 348: 1234-1237

41 Yin $\mathrm{G}$, Zhao $\mathrm{H}$, Jiang $\mathrm{H}$, et al. Precursor engineering for all-inorganic $\mathrm{CsPbI}_{2} \mathrm{Br}$ perovskite solar cells with $14.78 \%$ efficiency. Adv Funct Mater, 2018, 28: 1803269

42 A Awadhia, SL Agrawal. Structural, thermal and electrical characterizations of PVA:DMSO: $\mathrm{NH}_{4} \mathrm{SCN}$ gel electrolytes. Solid State Ionics, 2007, 178: 951-958

43 Lee JW, Kim HS, Park NG. Lewis acid-base adduct approach for high efficiency perovskite solar cells. Acc Chem Res, 2016, 49: 311319

44 Zai $\mathrm{H}$, Zhang D, Li L, et al. Low-temperature-processed inorganic perovskite solar cells via solvent engineering with enhanced mass transport. J Mater Chem A, 2018, 6: 23602-23609

45 Zhang X, Xu B, Zhang J, et al. All-inorganic perovskite nanocrystals for high-efficiency light emitting diodes: Dual-phase $\mathrm{CsPbBr}_{3}-\mathrm{CsPb}_{2} \mathrm{Br}_{5}$ composites. Adv Funct Mater, 2016, 26: 45954600

46 Duong $\mathrm{T}, \mathrm{Wu} \mathrm{YL}$, Shen $\mathrm{H}$, et al. Rubidium multication perovskite with optimized bandgap for perovskite-silicon tandem with over 26\% efficiency. Adv Energy Mater, 2017, 7: 1700228 
47 Li J, Zhang $\mathrm{H}$, Wang $\mathrm{S}$, et al. Synthesis of all-inorganic $\mathrm{CsPb}_{2} \mathrm{Br}_{5}$ perovskite and determination of its luminescence mechanism. RSC Adv, 2017, 7: 54002-54007

48 Jeon NJ, Noh JH, Kim YC, et al. Solvent engineering for highperformance inorganic-organic hybrid perovskite solar cells. Nat Mater, 2014, 13: 897-903

49 Zhang S, Wu S, Chen W, et al. Solvent engineering for efficient inverted perovskite solar cells based on inorganic $\mathrm{CsPbI}{ }_{2} \mathrm{Br}$ light absorber. Mater Today Energy, 2018, 8: 125-133

50 Dursun I, De Bastiani M, Turedi B, et al. $\mathrm{CsPb}_{2} \mathrm{Br}_{5}$ single crystals: Synthesis and characterization. ChemSusChem, 2017, 10: 37463749

51 Wang $\mathrm{KH}, \mathrm{Wu} \mathrm{L}$, Li L, et al. Large-scale synthesis of highly luminescent perovskite-related $\mathrm{CsPb}_{2} \mathrm{Br}_{5}$ nanoplatelets and their fast anion exchange. Angew Chem Int Ed, 2016, 55: 8328-8332

52 Rodová M, Brožek J, Knížek K, et al. Phase transitions in ternary caesium lead bromide. J Thermal Anal Calorimetry, 2003, 71: 667673

Acknowledgements This work was supported by the National Natural Science Foundation of China (51802241 and 91963209), the Fundamental Research Funds for the Central Universities (WUT: 2019IVB055 and 2019IVA066), ARC Discovery Grant DP150104483, ARC Centre of Excellence in Exciton Science (CE170100026), and the Australian Government through the Australian Renewable Energy Agency (ARENA). The authors acknowledge the use of facilities within the Monash Centre for Electron Microscopy and the Monash X-ray Platform.

Author contributions Li W, Rothmann MU, Ethridge J, Bach U, and Cheng YB conceived and designed the experiment. Li W and Zhu B carried out the sample preparation and solar-cell fabrication. Li W, Rothmann MU, Choo YY, and Liu A conducted the CL characterization. Li W, Zhu B, and Choo YY carried out the XRD analysis. Chen W and Wen X characterized the TRPL decay traces. Pai N conducted the FTIR analysis. All authors contributed to the discussion of the results and the writing of the manuscript.

Conflict of interest The authors declare that they have no conflict of interest.

Supplementary information Experimental details and supporting data are available in the online version of the paper.

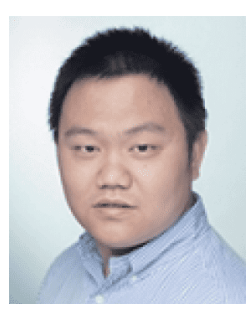

Wei Li is a full professor at Wuhan University of Technology (WHUT). He received his Bachelor's and Master's degrees from WHUT in 2006 and 2009, respectively. In 2013, he obtained his $\mathrm{PhD}$ degree from the University of New South Wales (UNSW). From 2013 to 2018, he worked as a research fellow at UNSW and Monash University. His current research interest focuses on high-efficiency perovskite solar cells and microstructure characterizations for photovoltaic materials.

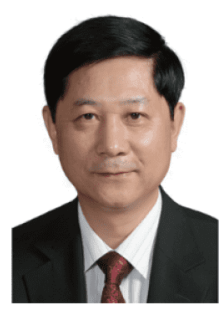

Yi-Bing Cheng is a full professor at WHUT, China, and emeritus professor of the Department of Materials Science and Engineering, Monash University, Australia. He is an elected fellow of the Australian Academy of Technology and Engineering. He specializes in inorganic materials processing and characterization. His current research interest is on perovskite solar cells.

\section{中间相促进 $\mathrm{CsPbIBr}$ 晶体生长以消除高效无机钙 钓矿太阳能电池的卤素相分离}

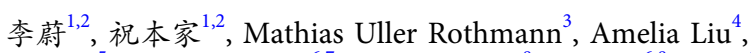
陈伟健 ${ }^{5}$, Yen Yee Choo ${ }^{6,7}$, Narendra Pai ${ }^{8}$, 毛文秷金, 张田 ${ }^{6,8}$, 鲍桥梁 ${ }^{7}$, 文小明 ${ }^{5}$, Udo Bach ${ }^{6,8,9,10^{*}}$, Joanne Etheridge ${ }^{7,11^{*}}$, 程一兵 $1,2^{*}$

摘要 混合卤化物钻钛矿材料由于易于调整光学带隙, 在叠层太阳 能电池、光伏建筑一体化和波长可调的发光器件等方面显示出诱 人的应用前景. 然而, 混合卤化物钻钠矿材料在光照或电荷注入的 条件下, 卤素离子会产生相分离, 从而影响光学带隙的稳定性和器 件性能的稳定性, 严重阻碍其应用前景. 本文中, 我们将过量 $\mathrm{PbBr}_{2}$ 或CsI加入到最初等化学计量比的 $\mathrm{PbBr}_{2}$ 和 CsI前驱体溶液中. 当 $\mathrm{PbBr}_{2}$ 过量时, 我们观察到 $\mathrm{CsPbIBr}$ 钙钛矿晶粒尺寸增大, 晶界和 $\mathrm{CsPbIBr} / \mathrm{TiO}_{2}$ 的异质结界面处的卤化物相分离得到抑制; 少数载 流子寿命增加, 电流密度-电压 $(J-V)$ 滞后减弱, 太阳能电池性能提 高. 然而当CsI过量时, 所观察到的结果与前者恰恰相反. 这是因为 在前驱体溶液中加入过量 $\mathrm{PbBr}_{2}$, 有利于形成 $\mathrm{Pb}(\mathrm{I}, \mathrm{Br})_{2} \cdot \mathrm{DMSO}$ 络合 物和准二维 $\mathrm{CsPb}_{2}(\mathrm{I}, \mathrm{Br})_{5}$ 中间相, 大大促进了 $\mathrm{CsPbIBr}_{2}$ 晶体的生长 和缺陷的消除. 因此, 通过控制 $\mathrm{CsPbIr}_{2}$ 前体溶液中的化学成分, 引 入中间相, 促进晶体的生长, 从而有效缓解混合卤化物无机 $\mathrm{CsPbIB}_{2}$ 太阳能电池中的卤化物相分离和器件的 $J-V$ 迟滞. 制备的 $\mathrm{Cs} \mathrm{PbIBr}_{2}$ 太阳能电池的最高光电转化效率达到 $9.37 \%$ (稳态效率达 到 $8.48 \%$ ), 最大外量子效率超过 $90 \%$. 